\title{
Zemin Analizleriyle Dinamik Davranış Özelliklerinin Belirlenmesine Yönelik Pilot Bir Çalışma: Kahramanmaraş İli Üngüt Mahallesi Örneği
}

\author{
Kübra Ceren ${ }^{1} \mathbb{D}$, Eyyüb Karakan ${ }^{1, *} \mathbb{D}$ \\ ${ }^{1}$ Kilis 7 Aralık Üniversitesi, Mühendislik Mimarlık Fakültesi, Inşaat Mühendisliği Bölümü, 79000, Kilis.

\section{Özet}

Can ve mal kaylplartyla maddi manevi kayıplara neden olan depremlerin, diğer doğal afetler gibi önlenmesi mümkün değildir, fakat depremlerin meydana getirebileceği hasarı en aza indirgemek mümkündür. Türkiye tektoniğinde önemli bir konuma sahip olan Kahramanmaraş ili’nin yüzölçümünün büyük çoğunluğu aktif faylara ev sahipliği yapmaktadır. Zeminlere ait mühendislik özelliklerinin belirlenmesi dinamik yükler altındaki zemin davranıslarının velveya meydana gelebilecek zararların en aza indirilebilmesinde büyük önem taşımaktadır. Bu nedenle Kahramanmaraş ili Üngüt Mahallesinde zemin dinamik davranış analizi yapılmıştır. Bu çalışma için Üngüt Mahallesinde yer alan 12 adet sondaj kuyusundan elde edilen veriler analizlerde kullanılmıştır. Bu çalıșma kapsamında Deepsoil programı yardımıyla çalıșma alanında belli noktalarda dinamik davranıș analizi yapılmıştır. Çalışma alanında doğrusal, frekans alanında eşdeğer doğrusal ve zaman alanında doğrusal olmayan analizler yapılarak zeminin dinamik davranışı hakkında bilgi edinilmiştir. Seçilen alanın zeminin dinamik davranış analizi 17 Ağustos 1999 Kocaeli (Mw=7.4) depreminin ivme kayıtları kullanılarak gerçekleştirilmiştir. Yapılan analizler sonucunda çalışma alanına ait ivme, tepki spektrumu ve amplifikasyon faktörü grafikleri elde edilmiştir. Bu çalışmada, analiz sonuçlarından elde edilen veriler değerlendirilerek, araştırmaya konu olan bölgedeki mevcut ve yeni yapılacak binaların temel zeminlerinin dinamik davranışlarının belirlenmesi hedeflenmiștir.

\section{Anahtar Sözcükler}

Deprem, Deepsoil, Zemin Davranış Analizi, Yerel Zemin Koşulları, Kahramanmaraş

\section{A Pilot Study on Determination of Dynamic Behavioral Characteristics by Soil Response Analyses: A Case concerning Üngüt District of Kahramanmaraş Province}

\begin{abstract}
It is not possible to prevent the earthquakes and other natural disasters which cause loss of lives and property, but it is possible to minimize the damages that they cause. The majority of the surface area of Kahramanmaras province, which can be considered a vulnerable zone in Turkish Tectonic System, underlies many active fault systems. Determination of engineering properties of soils is of great importance in determination of soil behavior and/or minimization of damages due to seismic action. For this reason, dynamic analyses were conducted in the Üngüt district of Kahramanmaraş and data obtained from 12 borings in Üngüt region were used in the analyses. In this scope, dynamic ground behavior analyses were performed on certain points in the study area by the use of Deepsoil software. Linear, frequency domain in the equivalent linear and time domain non-linear analysis have been carried out to obtain information about the dynamic behavior of the local soil conditions. Dynamic behavior analysis of the selected area was carried out using the acceleration recordings of the 17 August 1999 Kocaeli $(M w=7.4)$ earthquake. As a result of the analyses, variation of acceleration, response spectrum and amplification factor were obtained. In this study, by evaluating the data obtained, it is aimed to determine the dynamic behavior of the foundations of the existing and new buildings.
\end{abstract}

Keywords

Earthquake, Deepsoil, Soil Behavior Analysis, Local Soil Conditions, Kahramanmaraş

\section{Giriş}

Geçmişten günümüze kadar binlerce insanın ölümüne yol açan ve maddi manevi kayıplara neden olan depremler en tehlikeli doğal afetlerden birisidir. Depremlerin engellenmesi diğer doğal afetler gibi mümkün değildir. Ancak, depremden meydana gelebilecek hasarları en aza indirmek mümkündür. Dünya'nın etkin deprem kuşaklarından birinin üzerinde olan ülkemizde bugüne kadar meydana gelen depremlerde birçok yapının yıkılması ya da hasar görmesindeki en önemli etkenlerin jeolojik ve geoteknik özellikler ile yapılaşmadaki yanlışlıklar olduğu gerçeğini ortaya çıkarmıştır (Taşdelen vd. 2015).

1-D eşdeğer doğrusal arazi tepki analizi, iyi bilinen ve çok kullanılan bir yöntemdir (Schnabel vd. 1972; Schnabel vd. 1973). Zemin profili boyunca yukarı doğru ilerledikçe deprem hareketlerinin dönüşümünü tahmin etmek için kullanılır. 
Kayma dalgalarının, tüm frekanslar boyunca sabit bir sönümleme oranına sahip visko-elastik malzeme olarak modellenen bir zemin profilinin yatay katmanları arasında homojen bir yarım uzay dikey yayılımını varsayar (Idriss ve Sun 1992). Bu hesaplamalar, frekans alanında gerçekleștirilerek, hesaplamaların hızını ve sayısal kararlılığııı büyük ölçüde artııır. Bununla birlikte, zeminin lineer olmayan tepkisini frekans bölgesinde modellemek için, yinelemeli bir prosedür gerekmektedir.

Kahramanmaraş'ın kuzeyindeki büyük dağ kuşakları ile güneyindeki çöküntü alanları arasında geçişi sağlayan Ahir dağı eteklerine kurulmuștur. İl merkezinin deniz seviyesinden yüksekliği 568 metre olup, il genelinde arazi yükseklikleri 350 ile 3000 metre arasında değişmektedir. Kahramanmaraş ili sınırları içerisinde yer alan önemli yükseltiler ve dağlar, aynı zamanda çok sık bir drenaj ve akarsu sistemini de beraberinde getirmektedir. Yükseltili bir yapıya sahip olan Kahramanmaraş ili'nin çukur kesimleri yükseltiye bağlı olarak yüksek bir yeraltı su seviyesine sahiptir. Yumuşak zemin tabakasının ve yeraltı suyu seviyesinin yüksek olmasından dolayı Kahramanmaraş ili’nin çukur kesiminde yer alan Üngüt Mahallesi'nde zemin güçlendirme teknikleri uygulanarak yapılaşmaya izin verilmektedir. Fakat dikkat edilmesi gereken bir diğer nokta ise bu bölgede zeminin dinamik davranış analizlerinin yapılmasıdır.

Özyazıcıŏlu vd. (2019) tarafından Erzincan ili zemin büyütmelerinin incelenmesi amacıyla yapılan mikrobölgeleme çalışmasında Devlet Su İşleri Genel Müdürlüğü'nce açılmış sondaj kuyularına ait veriler kullanılmıştır. Eşdeğer-doğrusal büyütme analizleri Edushake/Proshake isimli program yardımıyla yapılmıştır. 8 farklı ana kaya verisi kullanılarak analizler yapılmış ve zemin yüzeyinde oluşan ortalama hareketin ivme-zaman geçmişi ve ortalama görünür spektral ivme (PSA) grafikleri elde edilmiştir.

Mikrobölgeleme çalışmasına altlık oluşturmak üzere Van Yüzüncü Yıl Üniversitesi kampüs zemininin dinamik davranış özelliklerinin belirlenmesi çalışması gerçekleştirilmiştir (Akın vd. 2015). Çalışmada belirtildiği üzere özellikle 1999 ve sonrasında ülkemizde yaşanan depremlerle meydana gelen can ve mal kayıları, depremin ve yarattı etkilerin sosyal ve ekonomik boyutunu bir kez daha ortaya koymuştur. Dinamik zemin özellikleri, deprem gibi doğal afetlerin de etkisi dikkate alınarak, mikrobölgeleme esasları doğrultusunda incelenmelidir. Bu amaçla Van Yüzüncü Yıll Üniversitesi kampüs alanında sondaj çalı̧̧alarından elde edilen bulgular ve jeofizik yöntemler ile dinamik zemin özellikleri ortaya konulmuştur. Elde edilen bulgular kampüs planlamasında yol gösterici olacaktır.

Bölgede Andırın sismik boşluğunda olduğu gibi 1989 'dan buyana her yıl $\mathrm{M}_{\mathrm{s}}>4$ birkaç depremin oluşması, büyük depremin habercisi mahiyetindedir. Bu durum 1998 Adana- Ceyhan depremi ile anlaşılmıştır. Aynı özellik yukarıda da değinildiği üzere Türkoğlu-Antakya sismik boşluğu için de geçerlidir (Biricik ve Korkmaz 2013).

Kayma dalga hızları $\left(\mathrm{V}_{\mathrm{s}}\right.$ ) kullanılarak Erciş yerleşim alanı ve çevresinin üç farklı deprem senaryosu için sıvılaşma analizleri yapılmıştır. Yapılan değerlendirmeler sonucunda, Erciş merkezinin yoğun olarak üzerinde bulunduğu eski göl çökellerinin sıvılaşma potansiyelinin "düşük-orta" olduğu belirlenmiştir. İnceleme alanının Van Gölüne yakın kıyı kesimleri ile inceleme alanının batısında sıvılaşma potansiyelinin diğer kesimlere göre daha yüksek olduğu hesaplanmıştır (Akkaya vd. 2017)

Zemin büyütme analizleri ve sahaya özel tasarım depremi özelliklerinin belirlenmesi çalışması tek boyutlu Shake91 yardımıyla analizler yapılmıştır (Ansal vd. 2011). Bu çalışmada belirtildiği üzere; deprem dalgaları içinden geçtikleri zemin tabakalarının mühendislik özelliklerini değiştirirken, zemin tabakaları da kalınlık ve özelliklerine bağlı olarak deprem dalgalarının özelliklerinin değiştirir. Bu değişim zemin yüzeyinde deprem ivme genliklerinin büyümesi veya küçülmesi, ivme zaman kayıtlarının süre ve frekans özelliğinin değişmesi şeklinde yapılmıştır. Olası bir depremin mevcut yapı ve bina stoğu üzerinde etkilerinin gerçeğe yakın bir biçimde belirlenmesinde zemin yüzeyindeki deprem özelliklerinin ve olası zemin davranışlarının hesaba katılması gerekli olduğu sonucuna varılmıştır.

Selçuk vd. (2007) tarafından Küçükçekmece-Sefaköy bölgesinde, kalınlığı 200 m’yi bulan zemin çökellerinin deprem sırasında oluşacak yüzey yer hareketi üzerindeki etkisini incelemek amacıyla, bir boyutlu eşdeğer lineer ve bir boyutlu ve iki boyutlu non-lineer dinamik davranış analizlerini EERA ve Deepsoil programları ile yapmışlardır. Her bir kesit için dinamik analizler yapılmış ve bu kesitler üzerinde arazi topoğrafyası ve formasyonlar göz önünde bulundurularak, seçilen noktalarda (bir boyutlu analizlerin yapıldığ noktalar) yüzey ivmesi ve spektral ivme değerleri belirlenerek karşılaştırılmıştır.

Bu çalışmanın amacı, Kahramanmaraş ili Üngüt mahallesindeki zeminlerin önceden yapılmış sondaj çalışmaları ve arazide sismik yöntemler kullanılarak belirlenmiş olan zeminin kayma dalgası hızı değerleri kullanılarak frekans alanında lineer, frekans alanında eşdeğer lineer ve zaman alanında doğrusal olmayan analiz yöntemleri kullanılarak zeminin dinamik davranışının belirlenmesi ve elde edilen parametrelerin karşılaş̧ırılmasıdır. Bu amaçla Deepsoil programı kullanılmıştır (Hashash vd. 2011). Analizler sonucunda seçilen bölge için ivme, tepki spektrumu ve amplifikasyon faktörü grafikleri elde edilmiştir.

\subsection{Inceleme Alanının Jeolojisi ve Depremselliği}

İnceleme alanını da kapsayan Kahramanmaraş kent merkezi ve civarındaki alanda yüzeyleyen birimlerin stratigrafik konumları ve jeoloji özellikleri Şekil 1'de gösterilmiştir (Kop vd. 2007). Çalışma alanı, Kahramanmaraş ili merkezinde riskli alan ilan edilen 29.9 hektar büyüklüğündeki bölge ve çevresi olmak üzere toplam 215.80 hektarlık alandır. İnceleme alanı batıdan doğuya doğru Oruç Reis, Malik Ejder, Barbaros, Hacı Bayram Veli ve Gayberli mahallelerini kapsamaktadır. 
Kahramanmaraş ili'nde yayılım gösteren formasyonlar; Koruk formasyonu, Eloğlu formasyonu, Koçali karmaşı̆̆ı, Kastel formasyonu, Besni formasyonu, Midyat formasyonu, Yenicekale formasyonu, Yavuzeli bazaltları ile alüvyon ve yamaç molozudur. Formasyonlardan da anlaşıldığı üzere Kahramanmaraş ili heterojen bir zemin dağılımına sahiptir. Kahramanmaraş ilinin Ahır dağı eteklerinde ve yeni yapılan Kuzey Çevre Yolu mevkiinde yayılım gösteren yamaç molozu irili ufaklı değişken boyutta farklı türdeki kaya parçalarından oluşan sert bir zemin tabakasına sahip iken, tekerek yolu, Boğaziçi mahallesi ve Üngüt mahallesine doğru inildikçe yumuşak alüvyon ve kil tabakası ile yüksek yer altı suyu seviyesi karşımıza çıkmaktadır.

Yeryüzü şekilleri bakımından engebeli bir arazi yapısına sahip olan Kahramanmaraş ilinden eğimin azaldığı yerlerde yer altı suyu zemin ve taşıma gücü için problem oluşturmaktadır. Kahramanmaraş ilinin özellikle güneyindeki düzlük alanlar ile Aksu ve Erkenez çayı gibi akarsu vadilerinde oldukça geniş yüzeylemeler sunan alüvyonlar ovanın değişik kesimlerinde 50-150 metre kalınlığa sahiptir. Özellikle yeni yapılaşmanın olduğu kesimlerde alüvyon ve kil tabakasının kalınlığı dikkat çekici boyutlardadır (Özşahin ve Eroğlu 2019).

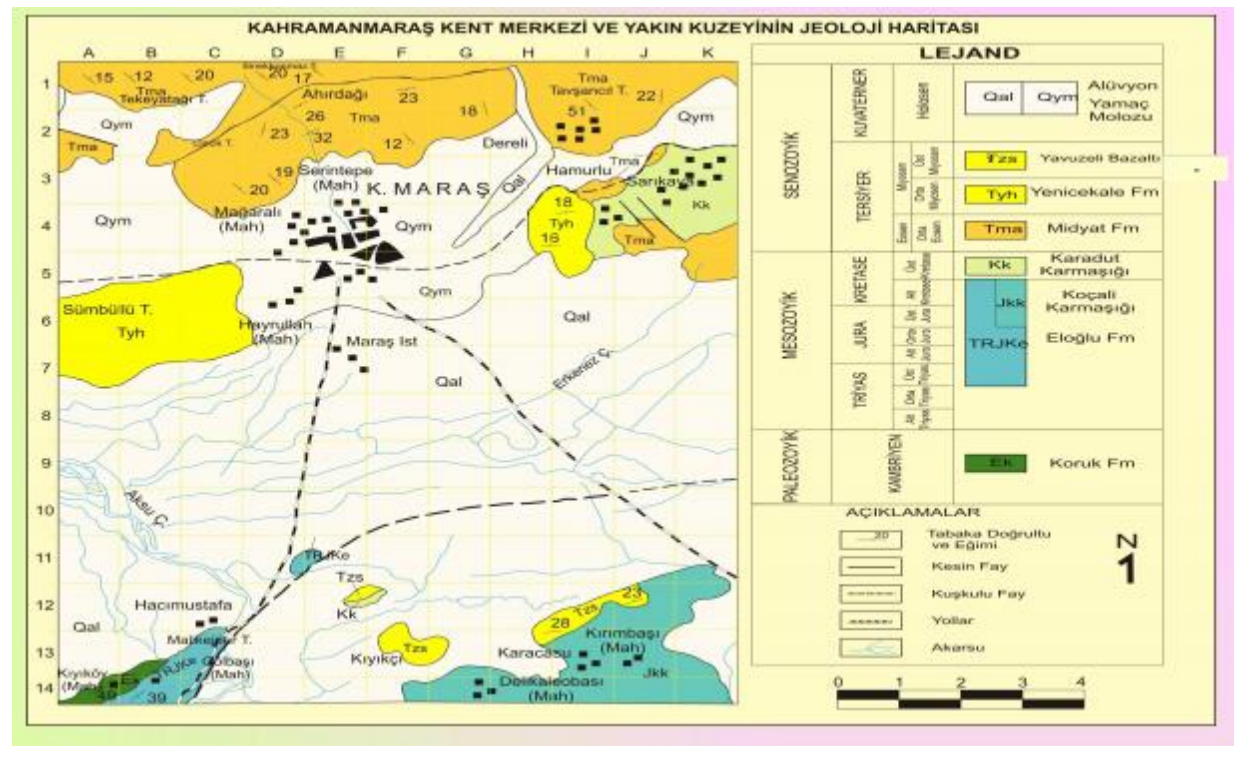

Şekil 1: Kahramanmaraş kent merkezi ve yakın kuzeyinin jeolojik haritası (Kop vd. 2007)

Kahramanmaraş ve yakın yöresinde, tarihsel dönemde meydana gelen, büyüklükleri ve yerleri belirlenebilen 13 adet orta büyüklükte depremler bulunmaktadır. Bu depremlerden 7 adedinin büyüklükleri 6-7 arasında olup, daha çok çalışma alanının batısında yoğunlaşmaktadır. Bunlardan biri $\mathrm{M}_{\mathrm{w}}=6.8$ büyüklüğünde 1544 yılında (Kondorskaya ve Ulomov 1999) Elbistan fayı üzerinde meydana gelmiştir. 1513 yılında meydana gelen ve büyüklüğü $\mathrm{M}_{\mathrm{w}}=7.5$ olarak tahmin edilen (Kondorskaya ve Ulomov 1999) bir başka deprem Yenicekale yakın batısında yer almaktadır. Her ne kadar bu depremin yeri Yenicekale yöresi olarak tahmin edilse de bu büyüklükteki bir depremin Doğu Anadolu Fayı (DAF) tarafından oluşturulmuş olma olasılığı yüksektir.

$\mathrm{Bu}$ depremin güneyinde yine Kondorskaya ve Ulomov (1999) tarafından 242 yılında meydana geldiği belirlenen $\mathrm{Mw}=7.6$ olan bir deprem meydana gelmiştir. Bu depremin çalışma alanında belirlenen aktif faylardan hangisi tarafından üretildiği bilinememektedir. Sirasıyla 1997 yılında büyüklüğü M=6.3 (Guidoboni vd. 1994), 1268 yılında büyüklüğü Mw=6.3 (Kondorskaya ve Ulomov 1999) ve 1894 yılında büyüklüğü $\mathrm{M}_{\mathrm{w}}=6.2$ (Kondorskaya ve Ulomov 1999) olarak tahmin edilen depremler Doğu Anadolu Fayı Kuzey Kolunun, Adana havzasına doğru oluşturduğu alt kollar üzerinde meydana gelmiş olmalıdır. DAF'ın güney kolunun Gölbaşı segmentinden kaynaklanmış olabilecek ancak, merkez üssü söz konusu segmentten $35 \mathrm{~km}$ güneyde belirtilen 1114 ve 1343 y1llarında sirasıyla $\mathrm{M}_{\mathrm{w}}=7.6$ ve $\mathrm{M}_{\mathrm{w}}=8.1$ büyüklüğünde (Kondorskaya ve Ulomov 1999) iki tarihsel depremin varlığı bilinmektedir. Aktif ve diri fayların varlığı, yumuşak zemin tabakası, yüksek yer altı suyu seviyesi ve tarihsel tektonik faaliyeti göz önüne alındığında Kahramanmaraş ili için zeminin dinamik davranış analizi büyük önem arz etmektedir.

\section{Materyal ve Yöntem}

Bu çalışma kapsamında Kahramanmaraş ili Üngüt Mahallesinde seçilen 6044 ada 6 parsel üzerinde zeminin dinamik davranış analizi yapılmıştır (Şekil 2). Zemin dinamik davranış analizlerini yapabilen birçok bilgisayar yazılımı mevcuttur. $\mathrm{Bu}$ çalışma kapsamında zeminlerin lineer, eşdeğer lineer ve non-lineer analizi yapabilen Illinois Üniversitesi'nde görevli Prof. Youssef M.A. Hashash ve öğrencileri tarafından geliştirilen Deepsoil programı kullanılarak analizler yapılmıştır. Deepsoil programı kendi bünyesinde meydana gelen büyük depremlerin ivme kayıtlarına göre analiz yapabilirken aynı zamanda kullanıcı tanımlı depreme göre de analiz imkânı da sunmaktadır. 


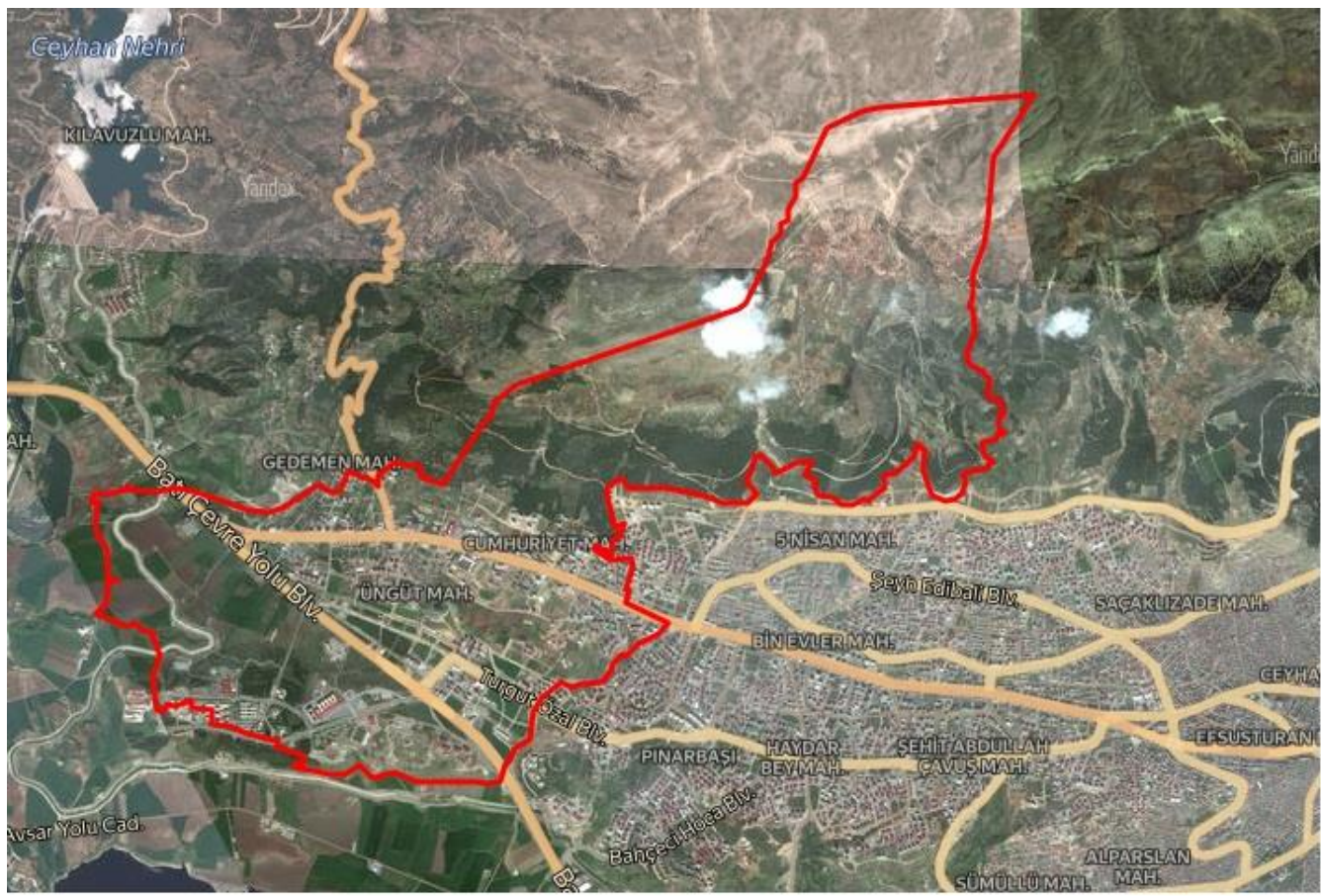

Şekil 2: Inceleme alanının haritası

Seçilen alanın Deepsoil programı yardımıyla frekans alanında lineer, frekans alanında eşdeğer lineer analizi ve zaman alanında doğrusal olmayan analizi yapılmıştır. Bu üç analiz sonuçları birbirleriyle karşılaştırılmıştır. Elde edilen analiz sonuçları zeminin dinamik davranışı hakkında bilgi sahibi olmamıza yardımcı olmuştur. Analizlere başlanmadan önce çalışma alanında yapılmış zemin etüt raporları detaylıca incelenmiş ve zemin etüt raporlarından elde edilen veriler programa veri girişi sırasında kullanılmıştır. Sondaj kuyuları incelendiğinde derinliği 15 metre olan 12 adet sondaj kuyusu açılmıştır (Şekil 2), sondaj kuyusu 4 için zemin profili 15 metre boyunca Tablo 3'de gösterildiği gibi killi çakıl olarak gözlemlenmiştir ve yer altı su seviyesi 5 metredir. Ana kaya derinliği 87.5 metre olarak hesaplanmıştır. Deepsoil programına veri girişi sırasında kullanmak üzere zemin tabakalarının birim hacim ağırlığı, kayma dalgası hızı (Vs) ve zemin tabakasının kalınlığı gerekmektedir. Zemin etüt raporundan zeminlerin birim hacim değerleri elde edilerek sisteme giriş yapılmıştır. Zemin tabakalarının kalınlığında ise sondaj logunda belirtilmiş olan kalınlık değerli kullanılmıştır. Çalışma kapsamında ana kaya seviyesinde 1999 yılında 7.4 büyüklüğünde meydana gelen Kocaeli depremindeki kayıt verisi kullanılarak tek boyutlu dinamik davranış analizleri yapılmıştır. Kayma dalgası hızı değeri jeofizik ölçümlerle de belirlenebileceği gibi literatürde belirtilen ampirik bağıntılar yardımıyla da belirlenebilir. Bu amaçla hem zemin etüt raporunda var olan sismik kırılma ve yansıma deneylerinden, hem de Standard Penetrasyon deneyi (SPT) sonucu elde edilen $\mathrm{N}_{30}$ ve Koni Penetrasyon Deneyi (CPT) sonucu elde edilen uç mukavemetine bağlı olarak ampirik bağıntılardan, aktif ve pasif kaynaklı yüzey dalgası yöntemlerinden ve mikrotremor ölçümlerinden elde edilen kayma dalgası hızı değerleri kullanılmıştır. Bazı araştırmacılar tarafından geliştirilen bu bağıntılar Tablo 1'de verilmiştir.

Tablo 1: Kayma dalgası hızının belirlenmesinde kullanılan ampirik bağıntılar

\begin{tabular}{|l|l|c|}
\hline Araştırmacı & Bă̆ıntı $\mathbf{V}_{\mathbf{s 3 0}}(\mathbf{m} / \mathbf{s n})$ & Zemin Cinsi \\
\hline Kanai vd. (1966) & $\mathrm{V}_{\mathrm{s}}=19 * \mathrm{~N}^{0.6}$ & Tüm \\
\hline Shibata (1970) & $\mathrm{V}_{\mathrm{s}}=31.7 * \mathrm{~N}^{0.54}$ & Kum \\
\hline Ohba ve Toriuma (1970) & $\mathrm{V}_{\mathrm{s}}=85.3 * \mathrm{~N}^{0.31}$ & Alüvial \\
\hline Ohta vd. (1972) & $\mathrm{V}_{\mathrm{s}}=87.2 * \mathrm{~N}^{0.36}$ & Kum \\
\hline Ohsaki ve Iwasaki (1973) & $\mathrm{V}_{\mathrm{s}}=81.4 * \mathrm{~N}^{0.39}$ & Tüm \\
\hline Imai ve Yoshimura (1975) & $\mathrm{V}_{\mathrm{s}}=92 * \mathrm{~N}^{0.329}$ & Tüm \\
\hline Imai ve Yoshimura (1970) & $\mathrm{V}_{\mathrm{s}}=89.9 * \mathrm{~N}^{0.341}$ & Tüm \\
\hline Seed ve Idriss (1981) & $\mathrm{V}_{\mathrm{s}}=41.6 * \mathrm{q}_{\mathrm{u}}{ }^{0.417} \mathrm{q}_{\mathrm{u}}(\mathrm{psi})$ & Tüm \\
\hline Lin vd. (1984) & $\mathrm{V}_{\mathrm{s}}=54.6 * \mathrm{~N}^{0.5}$ & Tüm \\
\hline İyisan (1996) & $\mathrm{V}_{\mathrm{s}}=65.58 * \mathrm{~N}^{0.6}$ & Tüm \\
\hline
\end{tabular}


Bu çalışma kapsamında İyisan (1996)'nın tüm zemin türlerinde geçerli olan denklem 1'de gösterilen bağıntısı kullanılarak kayma dalgası hızı $\left(\mathrm{V}_{\mathrm{s}}\right)$ hesaplanmıştır.

$$
V_{s}=51.5 * N^{0.516}
$$

Çalışmada literatürde sıkça kullanılan kayma dalgası hızı için verilen ampirik bağıntılar (Tablo 1) kullanılarak sondaj kuyusu 4 için kayma dalgası hızları hesaplanarak Tablo 2 oluşturulmuştur. Elde edilen sonuçlar, en küçük kayma dalgası hızının ( $V_{s}=196.27$ m/sn) Kanai vd. (1966) bağıntısı ile elde edildiğini göstermiştir. Yapılan çalışmada, Ohsaki ve Iwasaki (1973) $\left(V_{s}=371.34 \mathrm{~m} / \mathrm{sn}\right)$, Seed ve Idriss (1981) $\left(V_{s}=382.2 \mathrm{~m} / \mathrm{sn}\right)$ ile İyisan (1996) $\left(V_{s}=383.7 \mathrm{~m} / \mathrm{sn}\right)$ bağıntıları kullanılarak elde edilen kayma dalgası hızlarının birbirlerine çok yakın sonuçlar verdiği görülmüştür. Imai ve Yoshimura (1975) ile Imai ve Yoshimura (1970) tarafından ampirik bağıntılar kullanılarak elde edilen kayma dalgası hızlarının \%10 ile \%15 arasında daha küçük değerler verdiği sonucuna varılmıştır.

Tablo 2: SK4 Numaralı sondaj kuyusu için kayma dalgası hızının farklı bağıntılarla karşılaştırılması

\begin{tabular}{|l|l|c|c|}
\hline Araştırmacı & Bağıntı $\mathbf{V}_{\mathbf{s 3 0}}(\mathbf{m} / \mathbf{s n})$ & Zemin Cinsi & $\begin{array}{c}\text { Kayma Dalgası } \\
\text { Huzı (m/sn) }\end{array}$ \\
\hline Kanai vd. (1966) & $\mathrm{V}_{\mathrm{s}}=19 * \mathrm{~N}^{0.6}$ & Tüm & 196.27 \\
\hline Ohsaki ve Iwasaki (1973) & $\mathrm{V}_{\mathrm{s}}=81.4 * \mathrm{~N}^{0.39}$ & Tüm & 371.34 \\
\hline Imai ve Yoshimura (1975) & $\mathrm{V}_{\mathrm{s}}=92 * \mathrm{~N}^{0.329}$ & Tüm & 331.02 \\
\hline Imai ve Yoshimura (1970) & $\mathrm{V}_{\mathrm{s}}=89.9 * \mathrm{~N}^{0.341}$ & Tüm & 338.93 \\
\hline Seed ve Idriss (1981) & $\mathrm{V}_{\mathrm{s}}=41.6^{*} \mathrm{q}_{\mathrm{u}}{ }^{0.417} \mathrm{q}_{\mathrm{u}}(\mathrm{psi})$ & Tüm & 382.20 \\
\hline Iyisan (1996) & $\mathrm{V}_{\mathrm{s}}=54.6^{*} \mathrm{~N}^{0.5}$ & Tüm & 383.70 \\
\hline
\end{tabular}

Çalışma alanında ve yakın çevresinde yapılan önceki çalışmalar incelendiğinde; yapılan sondajların hepsi derinliği 15-20 metre arasında değişen sı̆̆ sondajlardır. Çalışma alanına yakın bir yerde yapılmış 30 metre derinliğinde 1 tane sondaj kuyusu vardır. 30 metre derinliğindeki sondaj numunesi üzerinde de İyisan (1996) bağıntısı kullanılarak $\mathrm{V}_{\mathrm{s} 30}$ kayma dalgası hızı elde edilmiştir ve elimizdeki 12 adet sondajda 30 metre derinlikteki kayma dalgası hızı değeri olarak $\mathrm{V}_{\mathrm{s} 30}=383.7 \mathrm{~m} / \mathrm{sn}$ değeri kullanılmıştır. Çalışma alanında ana kaya derinliğini belirten herhangi bulguya rastlanılmamıştır. UBC97' ye göre kayma dalgası hızının 760 m/sn'ye ulaştı̆̆ı yer mühendislik ana kayası olarak kabul edilmiştir.

Ana kaya derinliğine ulaşmak için $\mathrm{V}_{\mathrm{s} 30}$ kayma dalgası hızı değeriyle derinliğe bağlı lineer interpolasyon yaparak ana kaya derinliği 87.5 metre olarak belirlenmiştir ve analizlerimizde ana kaya derinliği olarak bu değer kullanılmıştır. Programa veri girişi sırasında kullanılan tüm veriler elde edildikten sonra analizler yapılmıştır ve analizler sonucunda elde edilen ivme, tepki spektrumu ve amplifikasyon faktörü grafikleri yorumlanarak seçilen bölgenin zemin davranış1 hakkında bilgi edinilmiştir.

Deepsoil programı yardımı ile frekans alanında lineer analiz, frekans alanında eşdeğer lineer analiz ve zaman alanında doğrusal olmayan analiz yapılabilmektedir. Deepsoil programı, kayma dalgalarına karşı homojen viskoelastik katmanlardan oluşan sistem tepkisinin hesaplanmasını sağlayan doğrudan dalga yayılım denklemi çözümüne dayanmaktadır. Frekans alanında lineer analiz yapılırken yenilenme adımı olarak en az 15 seçilerek analiz yapılır, ivme ve tepki spektrumu grafikleri elde edilir. Frekans alanında eşdeğer lineer analizin, frekans alanında lineer analizden farkı, zemin türüne göre başvuru eğrisi tanımlanmasıdır. Başvuru eğrisi kum zeminler için Seed ve Idriss (1970) ve kil zeminler için Vucetic ve Dobry (1991) eğrileri seçilmiştir. Bu seçilen alanda zemin tabakamız kum zemin olduğu için başvuru eğrisi olarak Seed ve Idriss (1970) eğrisi kullanılmıştır. Zamanalanın doğrusal olmayan analizde diğer analizlerden farklı olarak eğri uydurma eğrisi seçimidir. Bu çalışma kapsamında Darendeli azaltma faktörü kullanılmıştır. Bu ampirik model, gerilme şekil değiştirme ilişkilerini ve dolayısıyla normalleştirilmiş kayma modülü indirgeme eğrilerini temsil etmek için değiştirilmiş bir hiperbolik zemin modelini kullanır. Modifiye hiperbolik zemin modeli için referans gerilme ve eğrilik katsayısı olmak üzere iki parametre kullanılır. Eğri uydurma eğrisi seçildikten sonra 'sığdır' ikonu yardımıyla tüm zemin tabakalarına ayrı ayrı eğri uydurma eğrisi tanımlanmış olur.

\section{Bulgular ve Tartışma}

$\mathrm{Bu}$ çalışma kapsamında Kahramanmaraş İli Üngüt Mahallesi’nde (Şekil 2) Deepsoil programı yardımıyla frekans alanında lineer, frekans alanında eşdeğer lineer ve zamanalanında doğrusal olmayan analizler yapılmıştır. Analizler sonucunda ivme, tepki spektrumu ve amplifikasyon faktörü grafiği elde edilmiştir. Deepsoil programı ile hem eşdeğer lineer hem de non-lineer analizler yapılabilirken EERA (2000) programı ile sadece eşdeğer lineer analiz yapılabilmektedir. Bu durumda zeminlerin deprem davranışı sırasında Deepsoil programı daha çok tercih sebebi olmuştur. Bir boyutlu dinamik davranış analizleri Deepsoil (2004) programı kullanılarak her bir kesit üzerinde arazi topoğrafyası ve formasyonlar göz önünde bulundurularak seçilen sondajlarda yapılmıştır. Bu noktalar için, zemin profili, tabaka kalınlıkları ve malzeme parametreleri tanımlanmıştır. 
Analizlerde kullanılan malzeme parametreleri zemin etüt raporu sonuçlarından elde edilerek girilmiştir. G/G $G_{\max }$ ve sönüm değişim eğrileri için, killi zeminlerde plastisite dikkate alınarak Vucetic ve Dobry (1991), alüvyon kesimler ve kumlu zeminler için Seed ve Idriss (1970) ve Idriss (1990) eğrileri kullanılmıştır.

Tablo 3: Sondaj Kuyusu 4 için veriler

\begin{tabular}{|c|c|c|c|c|c|c|c|c|}
\hline \multirow{3}{*}{ SK4 } & \multicolumn{7}{|c|}{ SO NDAJ YERI / PROJE: } & $\operatorname{Derinlik}(\mathbf{m})$ \\
\hline & \multicolumn{7}{|c|}{ ÜNGÜT MAHALLESI } & \multirow{2}{*}{$15 \mathrm{~m}$} \\
\hline & ADA: & \multicolumn{3}{|c|}{6044} & \multicolumn{2}{|c|}{ PARSEL: } & 4 & \\
\hline & \multicolumn{7}{|c|}{ KOORDİNAT-Y: } & Y.A.S.S. \\
\hline & \multicolumn{7}{|c|}{ KOORDINAT-X: } & DERİNLİK \\
\hline & \multicolumn{7}{|c|}{ DENEYLER VE HES APLAMALAR } & $5 \mathrm{~m}$. \\
\hline & \multicolumn{4}{|c|}{ Zemin Deneyleri } & \multicolumn{3}{|c|}{ HESAPLAMALAR } & \multirow{3}{*}{ 恣: } \\
\hline$\underbrace{\dot{\Xi}}_{i=0}$ & \multicolumn{3}{|c|}{ S.P.T. } & & \multirow{2}{*}{ 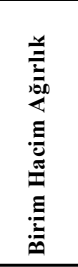 } & \multirow{2}{*}{ 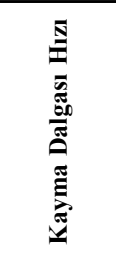 } & \multirow{2}{*}{ 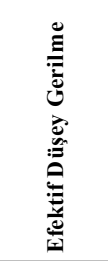 } & \\
\hline 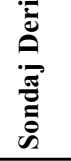 & $\because$ & లి & 18 & 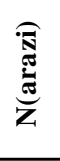 & & & & \\
\hline 1 & & & & & & & & $m m m m m m$ \\
\hline 2 & 5 & 8 & 10 & 18 & 19 & 228.84 & 19 & $-0-0-0-0-0-0-0-$ \\
\hline 3 & & & & & & & & $-0-0-0-0-0-0-0-$ \\
\hline 4 & 6 & 9 & 11 & 20 & 19 & 241.62 & 57 & $-0-0-0-0-0-0-0-$ \\
\hline 5 & & & & & & & & $-0-0-0-0-0-0-0-$ \\
\hline 6 & 4 & 7 & 11 & 18 & 19 & 228.84 & 85 & $-0-0-0-0-0-0-0-$ \\
\hline 7 & & & & & & & & $-0-0-0-0-0-0-0-$ \\
\hline 8 & 4 & 7 & 10 & 17 & 19 & 222.19 & 103 & $-0-0-0-0-0-0-0-$ \\
\hline 9 & & & & & & & & $-0-0-0-0-0-0-0-$ \\
\hline 10 & & & & & 19 & 236.87 & 121 & $-0-0-0-0-0-0-0-$ \\
\hline 11 & & & & & & & & $-0-0-0-0-0-0-0-$ \\
\hline 12 & & & & & 19 & 251.55 & 139 & $-0-0-0-0-0-0-0-$ \\
\hline 13 & & & & & & & & KİLLİ ÇAKIL \\
\hline 14 & & & & & 19.5 & 266.23 & 158 & $-0-0-0-0-0-0-0-$ \\
\hline 15 & & & & & & & & $-0-0-0-0-0-0-0-$ \\
\hline 16 & & & & & 19.5 & 280.91 & 177 & $-0-0-0-0-0-0-0-$ \\
\hline 17 & & & & & & & & $-0-0-0-0-0-0-0-$ \\
\hline 18 & & & & & 19.5 & 295.59 & 196 & $-0-0-0-0-0-0-0-$ \\
\hline 19 & & & & & & & & $-0-0-0-0-0-0-0-$ \\
\hline 20 & & & & & 20 & 310.27 & 216 & $-0-0-0-0-0-0-0-$ \\
\hline 21 & & & & & & & & $-0-0-0-0-0-0-0-$ \\
\hline 22 & & & & & 20 & 324.95 & 236 & $-0-0-0-0-0-0-0-$ \\
\hline 23 & & & & & & & & $-0-0-0-0-0-0-0-$ \\
\hline 24 & & & & & 20 & 339.63 & 256 & $-0-0-0-0-0-0-0-$ \\
\hline 25 & & & & & & & & $-0-0-0-0-0-0-0-$ \\
\hline 26 & & & & & 20 & 354.30 & 276 & $-0-0-0-0-0-0-0-$ \\
\hline 30.5 & & & & & 20.5 & 383.70 & 323.25 & $-0-0-0-0-0-0-0-$ \\
\hline 40 & & & & & 21 & 445.76 & 427.75 & $-0-0-0-0-0-0-0-$ \\
\hline 50 & & & & & 21 & 521.09 & 537.75 & $-0-0-0-0-0-0-0-$ \\
\hline 60 & & & & & 21.5 & 586.42 & 652.75 & $-0-0-0-0-0-0-0-$ \\
\hline 70 & & & & & 21.5 & 651.75 & 767.75 & $-0-0-0-0-0-0-0-$ \\
\hline 80 & & & & & 21.5 & 717.08 & 882.75 & $-0-0-0-0-0-0-0-$ \\
\hline 87.5 & & & & & 22 & 766.00 & 972.75 & ANAKAYA \\
\hline
\end{tabular}


Deprem dalgaları, sinüs dalgaları gibi tek bit harmonik dalga şeklinde değildir. Deprem dalgalarının yapılarda hasar verici özelliği genelde $0.1 \mathrm{~Hz}$ ile $10 \mathrm{~Hz}$ arasındaki değerlerde oluştuğu gözlemlenmiştir. Deprem dalgaları aynı zamanda zemin içerisinde yayıldıkları ortam özelliklerine göre de şekillenmektedir. Eğer yumuşak zemin ortamında ilerlerse, farklı frekanslar için deprem dalgaları aynı şekilde tepki vermemektedir, bu durum büyütmenin frekansa bağımlı olduğunu göstermektedir. Yüzeydeki en büyük ivme değeri ile mühendislik tasarımı için davranış spektrumu oluşturulur (Ansal vd. 2011).

Eşdeğer lineer analiz, frekans alanındaki, yalnızca gerçek lineer olmayan davranışının yaklaşık bir değeri olan ve zemin katmanlarının kayma deformasyonu ile uyumlu zemin özelliklerini elde etmek için yinelemeli bir süreç kullanan lineer analiz yöntemidir. Zeminin viskoelastik davranışına dayanan bu yöntemde, zemin özelliklerinin değiştirilmesi, çözüme ulaşana ve uygun moddaki deformasyonları elde edene kadar adım adım doğrusal analiz tekrarlanır. Öte yandan, yumuşak zemin tabakaları veya güçlü sismik hareketlere maruz kalan alanlar için, eşdeğer doğrusal yöntemin kullanımı, mevcut gözlemlerle uyuşmayan sonuçlar da üretebilmektedir (Hashash vd. 2010). Bununla birlikte, eşdeğer doğrusal yaklaşım, sadeliği ve güvenli tarafta kalması nedeniyle deprem simülasyonu altındaki makul bir zemin tepkisi tahmininin amplifikasyon dalga değerlerinin hesaplanmasında özel bir pratik önemine sahiptir.

Bu makalede, ilk adımda, frekans alanında lineer analiz yöntemi kullanılarak Kocaeli depremi için tepki spektrumu değerleri elde edilmiştir. İnceleme alanında yer alan 12 adet sondaj verisi kullanılarak gerçekleştirilmiştir. Deepsoil programında ilk olarak frekans alanında lineer analiz yöntemi kullanılarak yapılan çalışmalar neticesinde her bir sondaja ait ivme zaman grafikleri, Tepki spektrumu-T (periyot) ve amplifikasyon-T (periyot) grafikleri Şekil 34'de gösterilmiştir.

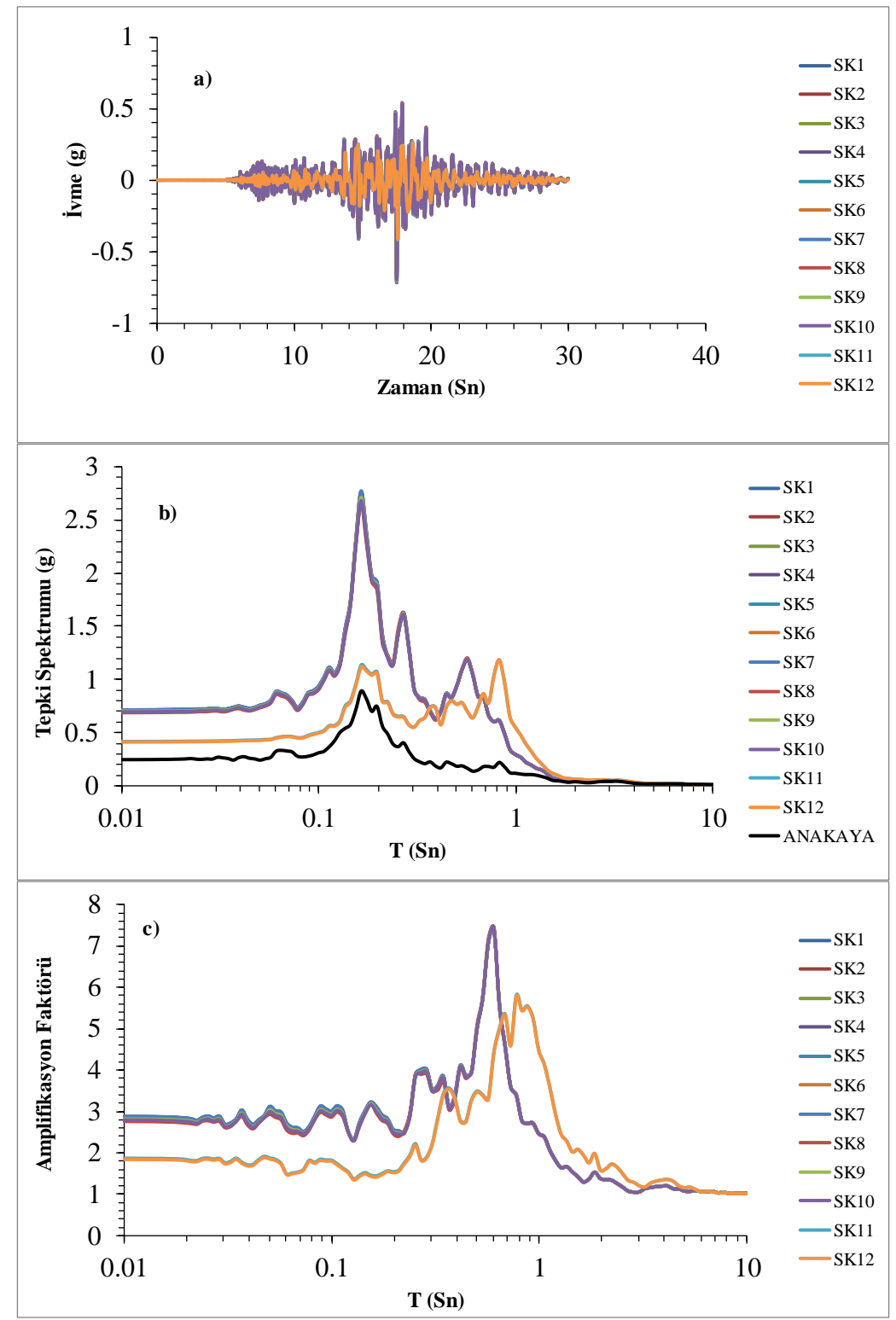

Şekil 3: Kocaeli deprem verisi kullanılarak Üngüt mahallesi için elde edilmiş frekans alanında lineer analiz a) ivme zaman, b) Tepki spektrumu- periyot (T) c) Amplifikasyon faktörü- periyot (T) sonuçları 
Deepsoil programı ile yapılan frekans alanında lineer analiz sonuçları incelendiğinde ilk 10 sondaj için elde edilen ivme zaman grafiği incelendiğinde 17. sn'de 0.69 (g) değerine ulaştığı ancak 11 ve 12 nolu sondajlarda ise aynı zaman için 0.41 (g) değeri elde edilmiştir (Şekil 3a). Şekil 3b'de ise yine aynı analiz için tepki spektrumu - periyot grafiği verilmiştir. Bu grafikte, 1-10 nolu sondajlar için 0.16 sn'de 2.60 değeri ile pik noktaya ulaşmıştır. 11 ve 12 nolu sondajlarda ise pik değer 1.08 olarak elde edilmiştir. Ana kaya için tepki spektrumu 0.89 olarak hesaplanmıştır. Frekans alanında lineer analiz için amplifikasyon faktörü periyot grafiği Şekil 3c'de gösterilmiştir. Şekilde görüldüğü üzere, 1-10 nolu sondajlarda 0.6 sn'de 7.42 değeri ile pik noktaya ulaşmıştır ve en fazla büyütme ilk on sondajdaki verilerden elde edilmiştir. 11 ve 12 nolu sondajlarda ise 0.77 sn'de 5.79 değeri elde edilmiştir. Periyot değerlerinin son iki sondaj için 0.2 sn kadar ötelendiği net bir şekilde görülmektedir. Frekans alanında lineer analiz sonuçları incelendiğinde zeminin aynı parsel üzerinde yer almasına rağmen farklı davranış özellikleri göstermektedir.

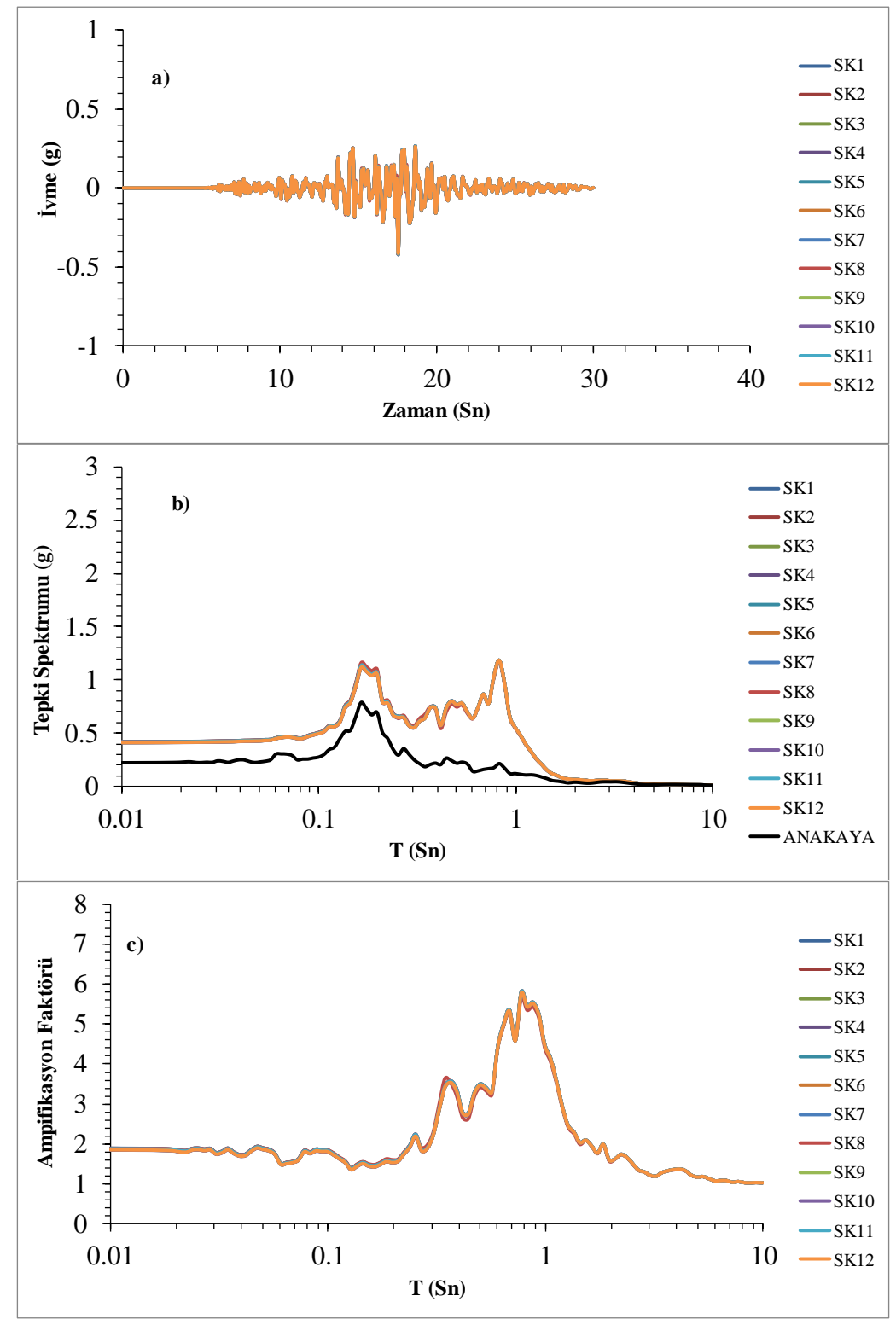

Şekil 4: Kocaeli deprem verisi kullanılarak Üngüt mahallesi için elde edilmiş frekans alanında eşdeğer lineer analiz a) ivme - zaman, b) Tepki spektrumu- periyot (T) c) Amplifikasyon faktörü- periyot (T) sonuçları

Şekil 4'de Kocaeli deprem verisi kullanılarak Üngüt mahallesi için frekans alanında eşdeğer lineer analiz yapılarak elde edilen ivme zaman, tepki spektrumu - periyot ve amplifikasyon faktörü - periyot grafikleri gösterilmiştir. İvme zaman grafiğinde on iki sondaj için 17 sn'de, 0.41 (g) olarak pik noktaya ulaşmıştır (Şekil 4a). Şekil 4b'de elde edilen tepki spektrumu - periyot grafiğinde on iki sondaj için 0.16 sn'de 1.11 (g) değeri elde edilmiştir. Ana kaya için tepki spektrumu değeri ise 0.16 sn'de 0.78 (g)'dir. Amplifikasyon faktörü değeri tüm sondajlar için 0.77 sn'de 5.78 olarak bulunmuştur. Şekil 4'de Kocaeli deprem verisi kullanılarak Üngüt mahallesi için zaman alanında doğrusal olmayan analiz yapılarak elde edilen ivme zaman, tepki spektrumu - periyot ve amplifikasyon faktörü - periyot grafikleri gösterilmiştir. 
İvme zaman grafiğinde on iki sondaj için 0.17 sn'de, 0.285 (g) olarak pik noktaya ulaşmıştır (Şekil 5a). Şekil 5b'de elde edilen tepki spektrumu - periyot grafiğinde on iki sondaj için 0.17 sn'de 0.99 (g) değeri elde edilmiştir. Ana kaya için tepki spektrumu değeri ise 0.17 sn'de 0.75 (g)'dir. Amplifikasyon faktörü değeri tüm sondajlar için 0.87 sn'de 5.39 olarak bulunmuştur.

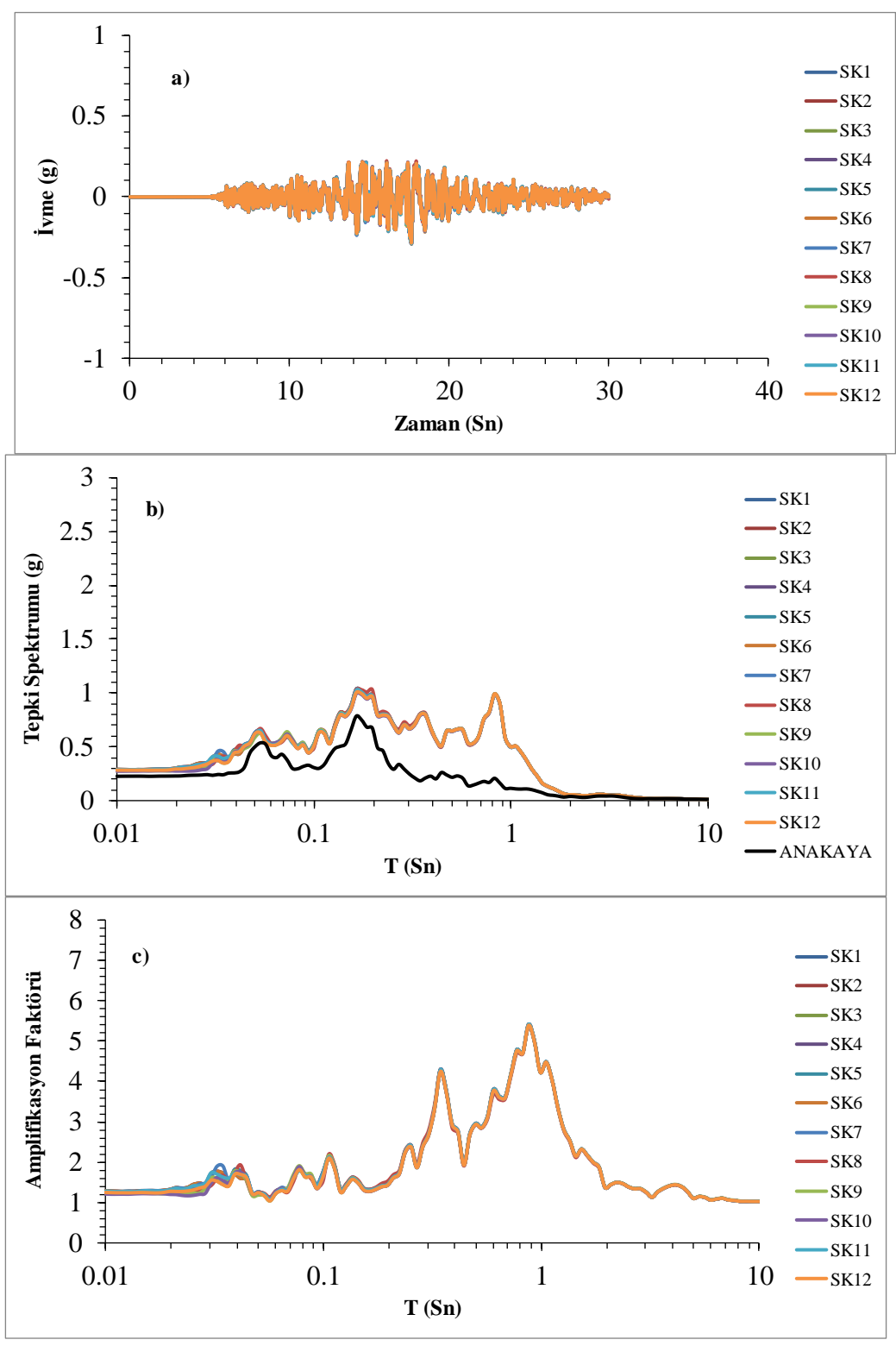

Şekil 5: Kocaeli deprem verisi kullanılarak Üngüt mahallesi için elde edilmiş zaman alanında doğrusal olmayan analiz a) ivme - zaman, b) Tepki spektrumu - periyot (T) c) Amplifikasyon faktörü - periyot (T) sonuçları

Yapılan analizde, Tablo 2'de, 6 farklı araştırmacının önerdiği ampirik bağıntılar kullanılarak sondaj kuyusu 4 (Tablo 3) için hem ana kaya hem de tabaka 1 için tepki spektrumu- periyot (T) grafikleri Şekil 6'da karşılaştırmalı olarak verilmiştir. Tabaka 1 için elde edilen tepki spektrumu değerlerinin İyisan (1996) ile Seed ve Idriss (1981) birbirine çok yakın sonuçlar verdiği görülmüştür. Tabaka 1'deki en büyük tepki spektrumu 0.17 sn'de $2.7 \mathrm{~g}$ olarak bulunmuştur (Şekil 6a). Anakaya için elde edilen en büyük tepki spektrumu değerleri için 0.17 sn'de $0.89 \mathrm{~g}$ olarak bulunmuştur. Tablo 2 'deki ampirik bağıntılarda ana kaya için elde edilen en küçük tepki spektrumu değeri ise 0.72g'dir. Farklı ampirik bağıntılar kullanılarak ana kaya için elde edilen tepki spektrumu değerlerinde belirgin bir fark bulunmamaktadır. 

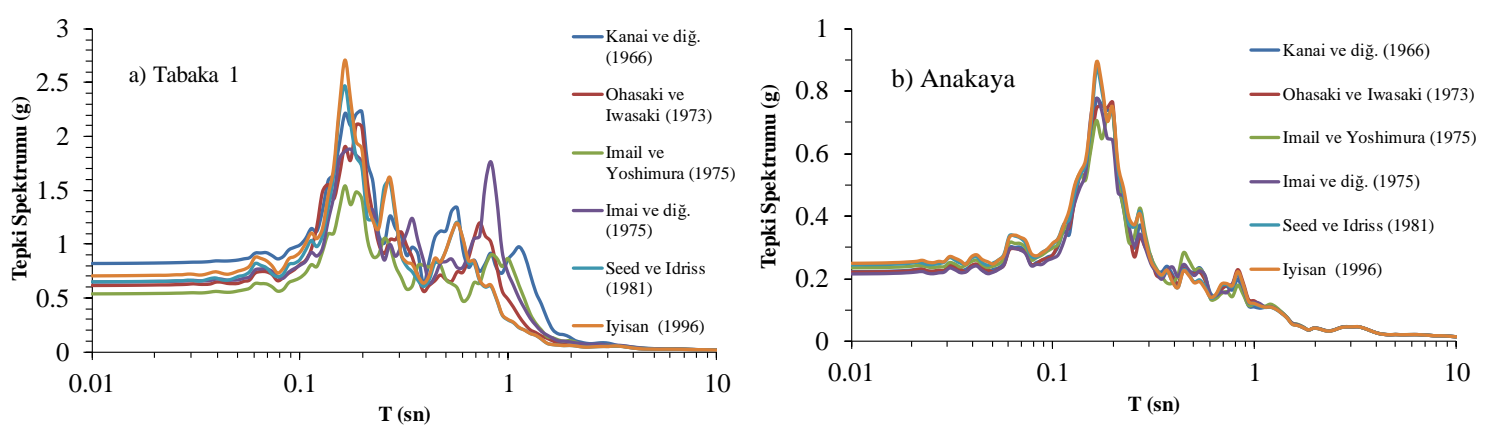

Şekil 6: Kocaeli deprem verisi kullanılarak Üngüt mahallesi için elde edilmiş frekans alanında lineer analiz için Tepki spektrumu - periyot (T) grafiklerinin a) Tabaka 1 ve b) anakaya için karşılaştırılması

\section{Sonuçlar}

Deepsoil programı ile yapılan bir boyutlu eşdeğer lineer analiz yönteminde, sondaj profili analizi sonucunda küçük sönüm değerleri için bile hareketi oldukça etkilediği görülmüştür. Farklı zemin türleri ana kayadan gelen deprem dalgalarının genliklerini büyütebildikleri gibi de aynı zamanda sönümleyebilirler. Bu nedenden yapıların altındaki zeminlerin dinamik özelliklerinin sahaya özel olarak belirlenmesi gerekmektedir. Elde edilen sonuçlar, çalışma bölgesine ait sismik tehlike ve zemin büyütme analizlerinin yapılması gerekliliğini ortaya koymuştur.

Elde edilen analizler incelendiğinde, aynı mahallede farklı sondajlar için yapılan üç farklı yöntem ile zemin cinsi ve özellikleri de göz önüne alındığında farklı sonuçlar ortaya çıkmıştır. İvme zaman grafiklerinde en büyük değerler frekans alanında lineer analiz yapılarak elde edilmiştir. En küçük ivme zaman grafiği değişimi ise zaman alanında doğrusal olmayan analiz ile bulunmuştur. Tepki spektrumu - periyot grafikleri için 2.6 (g) değeri ile frekans alanında lineer analiz yapılarak elde edilmiştir. Buna karşın zaman alanında doğrusal olmayan analizde ise bu değer 0.99 (g) olarak tespit edilmiştir. Farklı periyotlarda amplifikasyon faktörü değerleri de farklı davranış göstermiştir. Aynı zamanda zaman alanında doğrusal olmayan analiz sonucu amplifikasyon faktörü pik değeri 0.87 sn'de iken, frekans alanında lineer analiz için bu değer 0.6 sn olarak elde edilmiştir. Frekans alanında lineer ve eşdeğer lineer analiz sonuçları kendi arasında karşılaştırıldığında, hem tepki spektrumu - periyot hem de amplifikasyon faktörü- periyot sonuçlarının lineer analiz sonucu bir miktar daha büyük olduğu görülmektedir.

İnceleme alanında yapılacak kazılarda stabilite problemleri ile karşılaşılabileceğinden stabiliteye yönelik gerekli analizler yapılmalı, inşaat kazısı öncesi yol, altyapı sistemleri ve komşu parsellerin güvenliğini sağlayacak tedbirler alınmalıdır. İnceleme alanında yer alan dolgu birimi taşıyıcı zemin niteliğinde olmadığından hafredilmeli, yapı yükleri Döngele Formasyonunun ayrışmamış kesimlerine taşıttırılmalıdır. Çalışma alanında kalınlığ 0.50 - 7.50 metreler arasında değişen kontrolsüz dolgu tabakası taşıyıcı zemin niteliğinde olmadığından harfedilmeli, yapı yükleri Alüvyon, yamaç molozu veya Döngele Formasyonunun mühendislik problemleri bulunmayan kesimlerine taşıttırılmalıdır. Dolgu altında yer alan alüvyon heterojen bir yapıya sahip olduğundan yapı yükleri ve zemin özelliklerine bağlı olarak farklı oturmalar, taşıma gücü problemi görülebilir. Bu alanlarda yapı yüklerinin homojen zemine taşıttırılması gerekmektedir.

\section{Teşekkür}

Bu çalışma Kilis 7 Aralık Üniversitesi Bilimsel Araştırmaları, Proje No: 12271 ile desteklenmektedir.

\section{Kaynaklar}

Akın M.K., Akın M., Akkaya İ., Özvan A., Üner S., Selçuk L., Tapan M., (2015), Mikrobölgeleme çalışmasına altlık oluşturmak üzere Van Yüzüncü Yıl Üniversitesi kampüs zemininin dinamik özelliklerinin belirlenmesi, Jeoloji Mühendisliği Dergisi, 39(1), 1-26.

Akkaya İ., Özvan A., Akin M., Akin M., Övün U., (2017), Kayma Dalgası Hızı (Vs) kullanılarak Erciş (Van) yerleşim alanının sivilaşma potansiyelinin değerlendirilmesi, Çukurova Üniversitesi Mühendislik Mimarlık Fakültesi Dergisi, 32(3), 55-68.

Ansal A., Tönük G., Kurtuluş A., (2011), Zemin Büyütme Analizleri ve Sahaya Özel Tasarım Depremi Özelliklerinin Belirlenmesi, 1. Türkiye Deprem Mühendisliği ve Sismoloji Konferansı 11-14 Ekim, ODTÜ, Ankara.

Biricik A., Korkmaz H., (2013), Kahramanmaraş̧’n Depremselliği, Marmara Coğrafya Dergisi, 3(1), 53-82.

Guidoboni E., Comastri A., Traina G., (1994), Catalogue of ancient earthquakes in the Mediterranean area up to the 10th century, Instituto Nazionaledi Geofisica, Rome, France, 504 ss.

Hashash Y.M.A., Philips C., Groholski D.R., (2010), Recent advances in nonlinear site response analysis, 5th International Conference on Recent Advances in Geotechnical Earthquake Engineering and Soil Dynamics, May 24-29, San Diego, California, USA.

Hashash Y.M.A, Groholski D.R, Phillips C.A, Park D, Musgrove M., (2011), DEEPSOIL 5.0, User Manual and Tutorial, 107 ss.

Idriss I.M., Sun J.I., (1992), User's manual for SHAKE91: a computer program for conducting equivalent linear seismic response analyses of horizontally layered soil deposits, Center for Geotechnical Modeling, Department of Civil and Environmental Engineering, University of California, USA. 
Imai T., Yoshimura Y., (1970), Elastic Wave Velocity and Soil Properties in Soft Soil (in Japanese), Tsuchi-ToKiso, 18, 17-22.

Imai T., Yoshimura M., (1975), The relation of mechanical properties of soils to $P$ and $S$-wave velocities for soil ground in Japan, Urana Research Institue, OYO Corporation, OYO Technical Note O7, Tokyo, Japan.

İyisan R., (1996), Zeminlerde kayma dalgası hızı ile penetrasyon deney sonuçları arasındaki bağıntılar, Teknik Dergi, 7(32), 11871199.

Kanai K., Tanaka T., Yoshizawa S., (1966), Onmicrotremors IX, Bulletin of the Earthquake Research Institute, University of Tokyo, 43, 577-588.

Kop A., Yeleser L., Özbek A., Bodur M.N., (2007), Kahramanmaraş ve yakın kuzeyindeki kuvarterner çökellerin jeolojik ve jeoteknik özellikkleri, Çukurova Üniversitesi Jeoloji Mühendisliği Bölümü, 30.Y11 Jeoloji Sempozyumu, 25-27 Ekim, Adana, ss.218-219.

Kondorskaya N.V., Ulomov V.I., (1999), Special catalogue of earthquakes of the Northern Eurasia from ancient times through 1995 (SECNE), Joint Institute of Physics of the Earth (JIPE), Russian Academy of Sciences, Moscow, Russia.

Lin J.S., Deng J.G., Su Y.A., (1984), Application of finite element method in the analysis of deep excavation, Research Report GT 90009, Department of Construction Engineering, National Taiwan Institute of Technology.

Ohba S., Toriumi I., (1970), Research on vibrational characteristics of soil deposits in Osaka, part 2, on velocities of wave propagation and predominant periods of soil deposits, Technical Meeting of Architectural Institute of Japan.

Ohta Y., Hara A., Niwa M., Sakano T., (1972), Elastic Moduli of Soil Deposits Estimated by N-values, Proceedings of the 7th Annual Conference, The Japanese Society of Soil Mechanics and Foundation Engineering, ss.265-268.

Ohsaki Y., Iwasaki R., (1973), On dynamic shear moduli and poisson's ratios of soil deposits, Soil and Foundation, 13(4), 61-73.

Özşahin E., Eroğlu İ., (2019), Erzincan kentinde yerel zemin özelliklerinin deprem duyarlılı̆̆ına etkisi, Doğal Afetler ve Çevre Dergisi, $5(1), 41-57$

Özyazıcığlu M., Dönmezçelik K., Orhan S.N., Özkan M.Y., (2019), Erzincan ili zemin büyütmelerine dayalı mikrobölgeleme çalışması, Doğal Afetler ve Çevre Dergisi, 5(2), 247-256.

Schnabel P., Seed H.B., Lysmer J., (1972), Modification of seismograph records for effects of local soil conditions, Bulletin of the Seismological Society of America, 62(6), 1649-1664.

Schnabel P., Seed H.B., Lysmer J., (1973), Erratum: modification of seismograph records for effects of local soil conditions, Bulletin of the Seismological Society of America, 63(2), 750.

Shibata T, (1970), The relationship between the $N$-value and $S$-wave velocity in the soil layer, Disaster Prevention Research Laboratory, Kyoto University, Kyoto, Japan.

Seed H.B., Idriss I.M., (1970), Soil moduli and damping factors for dynamic response analyses, Report No. EERC 70-10, Earthquake Engineering Resource Center, University of California, Berkeley, California, USA.

Seed H.B., Idriss I.M., (1981), Evaluation of liquefaction potential of sand deposits based on observations of performance in previous earthquakes, ASCE National Convention: In Situ Testing to Evaluate Liquefaction Susceptibility, 81-544.

Selçuk M.E., Kılıç H., Özaydin K., (2007), Kalın zemin çökellerinde eşdeğer-lineer ve non-lineer analiz sonuçlarının karşılaştırılmasıı, Altıncı Ulusal Deprem Mühendisliği Konferans1, 16-20 Ekim, İstanbul, ss.187-198.

Taşdelen S., Akyol E., Çelik B., (2015), Işıklı Beldesi (Denizli) yerleşim alanının jeolojik ve jeoteknik özellikleri, Adıyaman Üniversitesi Mühendislik Bilimleri Dergisi, 3(2015), 1-15.

Vucetic M., Dorby R., (1991), Effect of soil plasticity on cyclic response, Journal of the Geotechnical Engineering Division, 117(1), 89-107. 